\title{
The Role of Oxygen Stoichiometry on Phase Stability, Structure, and Magnetic Properties of $\mathrm{Sr}_{2} \mathrm{ColrO}_{6-\delta}$
}

\author{
D. Mikhailova, ${ }^{, \dagger, \ddagger}$ N. Narayanan, ${ }^{\dagger, \ddagger}$ W. Gruner, ${ }^{\dagger}$ A. Voss, ${ }^{\dagger}$ A. Senyshyn, ${ }^{\ddagger}$ D. M. Trots, ${ }^{\S}$ H. Fuess, ${ }^{\ddagger}$ and \\ H. Ehrenberg ${ }^{\dagger}$,‡ \\ ${ }^{\dagger}$ Institute for Complex Materials, IFW Dresden, Helmholtzstrasse 20, D-01069 Dresden, Germany, \\ *Institute for Materials Science, Technische Universität Darmstadt, Petersenstrasse 23, D-64287, \\ Darmstadt, Germany, and ${ }^{\S}$ Bavarian Research Institute of Experimental Geochemistry and Geophysics, \\ University of Bayreuth, Universitätsstrasse 30, D-95440, Bayreuth, Germany
}

Received May 15, 2010

\begin{abstract}
The phase stability, crystal structure, and magnetic properties of perovskite-like nonstoichiometric $\mathrm{Sr}_{2} \mathrm{ColrO}_{6}-\delta$ were studied. Oxygen deficiency can be well controlled and reversibly varied up to $\delta=0.33$. A single phase exists at least for partial oxygen pressures between $10^{-5}$ and 1 bar at $1273 \mathrm{~K}$, followed by phase decomposition at higher temperature with the elimination of metallic Ir and the formation of a new phase with approximately $\mathrm{Sr}_{3} \mathrm{ColrO}_{6}$ composition crystallizing in $\mathrm{K}_{4} \mathrm{CdCl}_{6}$ structure type. The structural features of $\mathrm{Sr}_{2} \mathrm{ColrO}_{6-\delta}$ are dependent on both temperature and oxygen content and were determined by synchrotron and neutron powder diffraction. Both the increasing amount of oxygen vacancies at constant temperature and increasing temperature at constant oxygen content result in the same higher crystal symmetry of $\mathrm{Sr}_{2} \mathrm{ColrO}_{6-\delta}$ : (1) The oxygen-stoichiometric phase $\mathrm{Sr}_{2} \mathrm{ColrO}_{6.00}$ is monoclinic $(12 / \mathrm{m}$ or $\left.P 2_{1} / n\right)$ at room temperature but cubic $(F m-3 m)$ for $\mathrm{Sr}_{2} \mathrm{ColrO}_{5.67}$. (2) A sequence of phase transitions

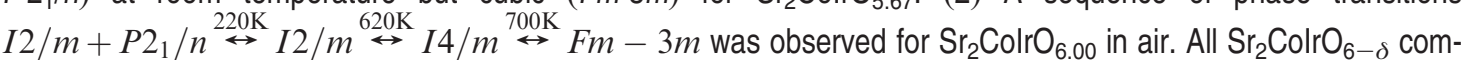
positions show weak ferromagnetism at low temperature with a canted but predominantly antiferromagnetic ground state. The magnetic ordering temperature decreases monotonously with increasing oxygen deficiency, while pronounced extrema are observed for the paramagnetic moment and the Curie-Weiss temperature at an oxygen deficiency $\delta \approx 0.10$, which corresponds to the $P 2_{1} / n \leftrightarrow 12 / \mathrm{m}$ phase transformation.
\end{abstract}

\section{Introduction}

The influence of oxygen nonstoichiometry on crystal structure, magnetism, and transport properties of perovskite-like materials was intensively investigated for $\mathrm{AA}^{\prime} \mathrm{O}_{3-\delta}$, with $\mathrm{A}$ being a rare earth element, $\mathrm{Ca}, \mathrm{Sr}$, or $\mathrm{Ba}$ and $\mathrm{A}^{\prime}$ being $\mathrm{Fe}$ or Co. ${ }^{1-3}$ These materials can be seen as potential oxygen storage materials and solid-state electrolytes due to two facts: First, the oxygen content in these phases can be significantly varied (up to $\delta=1$ for $\mathrm{Co}$ ) due to the ability of $\mathrm{Fe}$ and $\mathrm{Co}$ to change reversibly their oxidation state from +2 to +4 . Second, they demonstrate high electronic and oxygen conductivity at elevated temperatures. $\mathrm{SrCoO}_{3-\delta}$ and $\mathrm{SrFeO}_{3-\delta}$ undergo some structural phase transitions depending on temperature and oxygen content. For example, a series of $\mathrm{SrCoO}_{(3 n-1) / n}$ phases, with $n=2$ and $4-8$, was prepared

*Corresponding author. E-mail: d.mikhailova@ifw-dresden.de. Telephone: +49351 4659846

(1) Shein, I. R.; Kozhevnikov, V. L.; Ivanovski, A. L. J. Phys. Chem. Solids 2006, 67, 1436-1439.

(2) Taguchi, H.; Shimada, M.; Koizumi, M. J. Solid State Chem. 1979, 29, 221-225.

(3) Karvonen, L.; Yamauchi, H.; Karppinen, M. Chem. Mater. 2008, 20, $7143-7147$ through a soft oxidation of $\mathrm{SrCoO}_{2.5}$ by $\mathrm{Br}_{2}$ in aqueous solution. $^{3}$

Structural, magnetic, and transport properties of complex oxides with a double perovskite structure type, containing $\mathrm{Sr}$, $3 \mathrm{~d}$ transition metal, such as $\mathrm{Fe}$ or $\mathrm{Co}$, and $4 \mathrm{~d}$ or $5 \mathrm{~d}$ transition metal, such as Mo, W, Re, or Os, should also be strongly dependent on the oxygen content. The relationship between the oxygen stoichiometry and the physical properties of double perovskites $\mathrm{A}_{2} \mathrm{MM}^{\prime} \mathrm{O}_{6-\delta}$ with two crystallographically different sites for $\mathrm{M}$ and $\mathrm{M}^{\prime}$ metals was studied only in a few works, for example, on $\mathrm{Sr}_{2} \mathrm{FeMoO}_{6-\delta},{ }^{4} \mathrm{Sr}_{2} \mathrm{MgMoO}_{6-\delta}{ }^{5}$ and $\mathrm{Sr}_{2} \mathrm{CoSbO}_{6-\delta},{ }^{6}$ although lower oxidation states of the transition metals allow for significant oxygen deficiencies $\delta$.

Recently we have synthesized a series of phases $\mathrm{La}_{2-x} \mathrm{Sr}_{x}$ $\mathrm{CoIrO}_{6.00}$ for the first time and investigated temperature and composition $(x)$ dependence of their crystal and magnetic structures. ${ }^{7}$ We have observed a correlation between electron

(4) Töpfer, J.; Kircheisen, R.; Barth, S. J. Appl. Phys. 2009, 105, $07 \mathrm{D} 712$.

(5) Bernuy-Lopez, C.; Allix, M.; Bridges, C. A.; Claridge, J. B.; Rossensky, M. J. Chem. Mater. 2007, 19, 1035-1043.

(6) Primo-Martín, V.; Jansen, M. J. Solid State Chem. 2001, 157, 76-85.

(7) Narayanan, N.; Mikhailova, D.; Senyshyn, A.; Trots, D. M.; Laskowski, R.; Blaha, P.; Schwarz, K.; Fuess, H.; Ehrenberg, H. Phys. Rev. B: Condens. Matter Mater. Phys. 2010, 82, 024403. 
configurations of $\mathrm{Co}$ and $\mathrm{Ir}$ on the $\mathrm{M}$ and $\mathrm{M}^{\prime}$ sites, which challenges the interpretation of oxidation and spin states of the transition metals. This complexity does not exist for perovskite-like materials $\mathrm{AMO}_{3-\delta}$, with only one transition metal $\mathrm{M}$ in the structure. Therefore, the oxygen nonstoichiometry in double perovskites can affect the resulting structural and magnetic properties via changes in the electronic structure of two different transition metals. In this work we have prepared the end member $\operatorname{Sr}_{2} \mathrm{CoIrO}_{6-\delta}(x=2)$ with different oxygen stoichiometries and have analyzed the structural behavior and the magnetic properties in dependence on temperature and oxygen content. Density functional theory (DFT) calculations performed in the work ${ }^{7}$ for a fully oxidized monoclinic $\mathrm{Sr}_{2} \mathrm{CoIrO}_{6}$ phase revealed rather a presence of a combination HS $-\mathrm{Co}^{3+} / \mathrm{LS}-\mathrm{Ir}^{5+}$.

\section{Experimental Section}

$\mathrm{Sr}_{2} \mathrm{CoIrO}_{6-\delta}$ samples were prepared by a solid-state reaction in air at $1373 \mathrm{~K}$ from stoichiometric mixtures of $\mathrm{CoO}$ (Alfa Aesar, 99.999\%), $\mathrm{IrO}_{2}$ (Umicore), and $\mathrm{SrCO}_{3}$ (Alfa Aesar, 99.99\%) during $24 \mathrm{~h}$. Specific oxygen deficiencies were obtained by annealing at different temperatures in Ar atmosphere with a different partial oxygen pressure. Phase analysis and determination of cell parameters were carried out using X-ray powder diffraction (XPD) with a STOE STADI P diffractometer (Mo $\mathrm{K} \alpha_{1}$ radiation) in flat-sample transmission mode.

The amount of $\mathrm{Sr}, \mathrm{Co}$, and $\mathrm{Ir}$ in all prepared samples were determined quantitatively by the inductively coupled plasma optical emission spectroscopy (ICP-OES) method (IRIS Intrepid II XUV, Thermo Fisher) using a 3:1 mixture of $\mathrm{HCl}$ (37\%, p.a. Fa. Merck) and $\mathrm{HNO}_{3}(65 \%$, p.a. Fa. Merck) for dissolving the samples. The absolute oxygen content of the samples as a reference point was measured by the carrier gas hot extraction method with a commercial oxygen analyzer TC 436DR (Leco, St. Joseph, U.S.A.). The powders were weighed (about $20 \mathrm{mg}$ ) into metallic capsules of tin and nickel $(0.2-0.4 \mathrm{~g})$. This pressed package was dropped into a degassed high-temperature graphite crucible which was electrically heated with a power-time program. Two IR-selective detectors registered simultaneously the formed reaction species $\mathrm{CO}$ and $\mathrm{CO}_{2}$. The calibration was carried out with $\mathrm{ZrO}_{2}$ for the $\mathrm{CO}$ detector and with carbon dioxide gas dosing for the $\mathrm{CO}_{2}$ detector. A reproducibility of $0.5 \%$ relative standard deviation (RSD) can be reached by this method, as shown for many oxides. ${ }^{8}$

Thermogravimetric analysis (TGA) was used to study the oxygen release during heating and the incrementation during cooling on about $100 \mathrm{mg}$ powder in a crucible of $\mathrm{Al}_{2} \mathrm{O}_{3}$ (STA 449 Jupiter, Netzsch, Selb, Germany) in the temperature range up to $1573 \mathrm{~K}$ under flowing gas atmosphere. Different oxygen partial pressures from 1 to $1 \times 10^{-5}$ bar $\mathrm{O}_{2}$ were applied. The oxygen release was checked by the coupling technique TGA with a quadrupole mass spectrometer (QMS) Prisma (Pfeiffer Vacuum, Asslar, Germany).

The crystal structure of $\mathrm{Sr}_{2} \mathrm{CoIrO}_{6-\delta}$ in dependence on temperature was analyzed by synchrotron powder diffraction at the beamline B $2^{9}$ at HASYLAB/DESY (Hamburg, Germany) and in dependence on both temperature and gas atmosphere (air or Ar) by neutron powder diffraction on SPODI at the FRM II in Garching near Munich (Germany).

The investigations with synchrotron radiation in the temperature range of $10-1173 \mathrm{~K}$ were performed for $\delta=0$ in a

(8) Gruner, W.; Fresenius J. Anal. Chem. 1999, 365, 597-603.

(9) Knapp, M.; Baehtz, C.; Ehrenberg, H.; Fuess, H. J. Synchrotron Radiat. 2004, 11, 328-334. quartz capillary in air in Debye-Scherrer mode using the on-site readable image-plate detector $\mathrm{OBI}^{10}$ and a He closedcycle cryostat or a STOE furnace equipped with a EUROTHERM temperature controller. Measurements were performed with a temperature step of $25 \mathrm{~K}$. Neutron diffraction measurements of phases with different oxygen contents $(\delta=0$ and 0.2 ) were performed between 3 and $300 \mathrm{~K}$ in air in cylindrical vanadium cans. Measurements up to $970 \mathrm{~K}$ were performed in sealed Ta tubes with $\mathrm{Ar}$ atmosphere inside the tubes. After heating and subsequent cooling, the samples were analyzed at room temperature again to check the temperature-induced changes.

All diffraction patterns have been analyzed by full-profile Rietveld refinements, using the software package WinPLOTR. ${ }^{11}$ In order to reduce the degree of correlation between B-site disorder and thermal displacement parameters, the structure model was refined with an isotropic approximation for the thermal parameters of all atoms, which were constrained into three groups: one value for all oxygen atoms, one for $\mathrm{Sr}$, and one common for Co and Ir atoms.

Magnetic properties of $\mathrm{Sr}_{2} \mathrm{CoIrO}_{6-\delta}$ with different oxygen stoichiometry have been studied with a superconducting quantum interference device (SQUID) from Quantum Design. Measurements were performed upon heating in field cooled (FC) and zero field cooled (ZFC) modes in the temperature range from 1.7 to $350 \mathrm{~K}$ and with applied field strengths up to $6 \mathrm{~T}$.

\section{Results and Discussion}

1. Synthesis, Determination of Oxygen Stoichiometry, and Phase Stability of $\mathrm{Sr}_{2} \mathrm{CoIrO}_{6-\delta}$. Single-phase samples $\mathrm{Sr}_{2} \mathrm{Co}_{1.00(2)} \mathrm{Ir}_{1.00(1)} \mathrm{O}_{6.03(3)}$ were obtained after slow cooling from 1273 to $1373 \mathrm{~K}$ to room temperature in air. Combined X-ray and neutron powder diffraction (Figure $1 \mathrm{a}$ and $\mathrm{b}$ and Table 1) reveal a monoclinic crystal structure with space group $I 2 / \mathrm{m}$ and lattice parameters $a=5.5642(2), b=5.5315(2)$, and $c=7.8462(4) \AA, \beta=$ $90.05(1)^{\circ}$, and $Z=2$. Figure $1 \mathrm{~b}$ shows two calculated patterns: one based on the $I 2 / \mathrm{m}$ model and the other on the $I 4 / m$ model. It is obvious that the resulting fit is considerably better for the $I 2 / \mathrm{m}$ model.

Preliminary thermogravimetric experiments have shown that $\mathrm{Sr}_{2} \mathrm{CoIrO}_{6-\delta}$ is stable in $\mathrm{Ar}$ atmosphere $\left(\mathrm{p}\left(\mathrm{O}_{2}\right) \leq 10^{-5}\right.$ bar) up to $1323 \mathrm{~K}$, which corresponds to a $\delta$ of about 0.35 and decomposes with elimination of metallic Ir at higher temperatures (Figure 2a). Mass spectrometric analysis detected only oxygen in the gas phase. The decomposition process is reversible and depends strongly on the oxygen partial pressure; after annealing of the decomposition products at $1423 \mathrm{~K}$ in air $\left(\mathrm{p}\left(\mathrm{O}_{2}\right)=0.21\right.$ bar $)$, only $\mathrm{Sr}_{2} \mathrm{CoIrO}_{6-\delta}$ was formed again. Oxygen deficiency $\delta$ of $\mathrm{Sr}_{2} \mathrm{CoIrO}_{6-\delta}$ in dependence on temperature was studied at different oxygen pressures (from $10^{-5}$ to $1 \mathrm{bar}$ ), the results are presented in Figure $2 \mathrm{~b}$. The initial oxygen content was set as 6.00, corresponding to $\delta=0$.

Due to the tendency of Ir-containing complex oxides to release the oxygen followed by Ir elimination in reducing atmosphere at $1400-1500 \mathrm{~K}$, the formation of new phases with different structure types is expected during decomposition. A similar behavior was observed, for example, for $\mathrm{Sr}_{2} \mathrm{MgMoO}_{6}$, with a similar double perovskite

(10) Knapp, M.; Joco, V.; Baehtz, C.; Brecht, H. H.; Berghaeuser, A.; Ehrenberg, H.; von Seggern, H.; Fuess, H. Nucl. Instrum. Methods Phys. Res., Sect. A 2004, 521, 565-570.

(11) Roisnel, T.; Rodriguez-Carvajal, J. Mater. Sci. Forum 2001, $378-381,118-123$. 
(a)

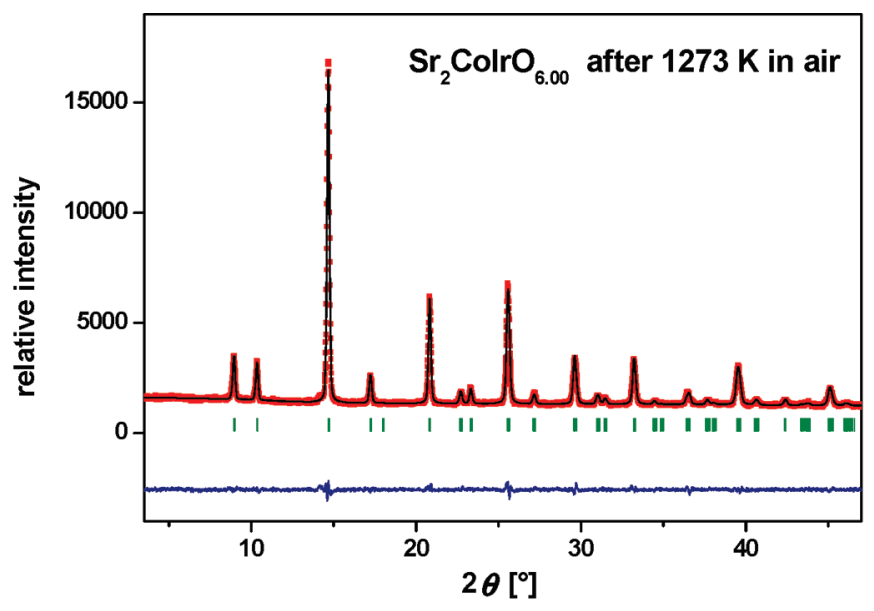

(b)
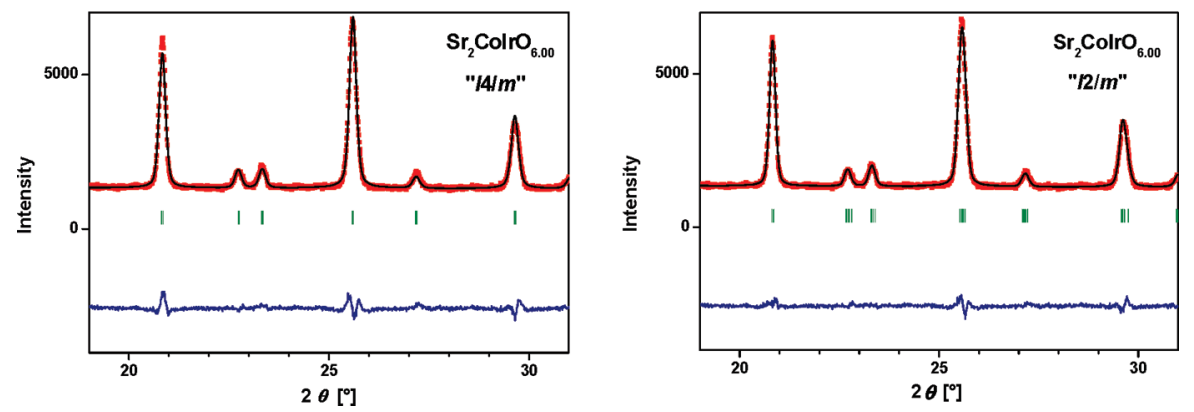

Figure 1. (a) X-ray diffraction pattern of an as prepared $\mathrm{Sr}_{2} \mathrm{CoIrO}_{6.00}$ sample, observed and calculated on the basis of S.G. $I 2 / m$ profiles together with their difference curve. (b) A section of the X-ray diffraction pattern of $\mathrm{Sr}_{2} \mathrm{CoIrO}_{6.00}$. From refinements in monoclinic (right) and tetragonal (left) models it is obvious that space group $I 2 / m$ describes experimental data significantly better.

structure. The formation of an oxygen-deficient perovskite $\mathrm{Sr}_{2} \mathrm{MgMoO}_{6-\delta}$ is followed by thermal decomposition at higher temperatures, where a Ruddlesden-Popper phase $\mathrm{Sr}_{3}\left(\mathrm{Mo}_{1-x} \mathrm{Mg}_{x}\right)_{2} \mathrm{O}_{7-\delta}$ (Figure 3b) is formed together with $\mathrm{MgO}$ and metallic Mo. ${ }^{5}$ All $(\mathrm{Mo}, \mathrm{Mg}) \mathrm{O}_{6}$ octahedra remain corner sharing. Alternatively, a formation of hexagonal perovskites with a different stacking sequence of pseudoclose packed layers of face- and corner-sharing octahedra could also be expected, like for example, in the $\mathrm{BaIr}_{1-x} \mathrm{Co}_{x} \mathrm{O}_{3-\delta}$ series, ${ }^{16}$ with an excess of Co aginst Ir. The structure of $\mathrm{BaCo}_{0.7} \mathrm{Ir}_{0.3} \mathrm{O}_{3}(x=0.7)$, built up from separate $(\mathrm{Co}, \mathrm{Ir})_{2} \mathrm{O}_{9}$ and $(\mathrm{Co}, \mathrm{Ir})_{3} \mathrm{O}_{12}$ units of face-sharing octahedra running along the $c$-axis with a random distribution of Co and Ir on the metal sites, is shown in Figure $3 \mathrm{c}$ as such an example. ${ }^{16}$ Up to now, there was no information about structurally related polymorphs in the $\mathrm{Sr}-\mathrm{Co}-\mathrm{Ir}-\mathrm{O}$ system. In the $\mathrm{Ca}-$ $\mathrm{Co}-\mathrm{Ir}-\mathrm{O}$ system, only $\mathrm{Ca}_{3} \mathrm{CoIrO}_{6}$, crystallizing in the $\mathrm{K}_{4} \mathrm{CdCl}_{6}$-type structure, is known. ${ }^{16}$

X-ray data of the decomposition products of $\mathrm{Sr}_{2}-$ $\mathrm{CoIrO}_{6-\delta}$ after annealing in Ar at $1573 \mathrm{~K}$ were successfully explained with the assumption of the formation of $\mathrm{Sr}_{3} \mathrm{CoIrO}_{6}$, isostructural to $\mathrm{Ca}_{3} \mathrm{CoIrO}_{6}$ (Figure 3d), together with metallic Ir and $\mathrm{Sr}_{2} \mathrm{CoIrO}_{6-\delta}$ (Figure 2c). This formation corresponds to the temperature- and oxygen pressure-dependent reaction $5 \mathrm{Sr}_{2} \mathrm{CoIrO}_{6-\delta} \Leftrightarrow 2$ " $\mathrm{Sr}_{3} \mathrm{CoIrO}_{6}$ " + $2 \mathrm{Sr}_{2} \mathrm{Co}_{1.5} \mathrm{Ir}_{0.5} \mathrm{O}_{6-\gamma}+2 \mathrm{Ir}+(3-5 \delta / 2+\gamma) \mathrm{O}_{2}$. In order to check the proposed stoichiometry of this new oxide in the

(12) Woodward, P. M. Acta Crystallogr. 1997, B53, 32-43.

(13) Serrate, D.; De Teresa, J. M.; Ibarra, M. R. J.Phys.: Condens. Matter 2007, 19, 023201.
$\mathrm{Sr}-\mathrm{Co}-\mathrm{Ir}-\mathrm{O}$ system, which is stable under reducing conditions, a mixture of $\mathrm{SrCO}_{3}, \mathrm{CoO}$, and $\mathrm{IrO}_{2}$ with overall composition " $\mathrm{Sr}_{3} \mathrm{CoIrO}_{6}$ " was held in an Ar-atmosphere at $1473 \mathrm{~K}$ for $24 \mathrm{~h}$ and successively cooled down to room temperature slowly. X-ray diffraction (XRD) data of this product confirm the composition $\mathrm{Sr}_{3} \mathrm{CoIrO}_{6}$ with a $\mathrm{K}_{4} \mathrm{CdCl}_{6}$ type structure and a small amount of metallic $\operatorname{Ir}(2.5 \% \mathrm{w} / \mathrm{w})$, see Figure 2d. The $\mathrm{Sr}_{3} \mathrm{CoIrO}_{6}$ structure contains onedimensional chains along the $c$-direction consisting of alternating face-sharing $\mathrm{CoO}_{6}$ trigonal prisms and $\mathrm{IrO}_{6}$ octahedra (Figure 3c). The chains are separated by Sr cations. A slight occupancy of Co on the respective Ir site (about 3\%) was also found and explains the presence of metallic Ir in the sample. Note that trigonal prismatic coordinations are rare in $3 \mathrm{~d}$ transition-metal oxides but rather common in complexes with three bidentate ligands, such as dithiolates or oxalates. ${ }^{14}$ Detailed structural and magnetic investigations of $\mathrm{Sr}_{3} \mathrm{CoIrO}_{6}$ will be reported elsewhere. ${ }^{15}$

The structure of $\mathrm{BaCo}_{0.7} \mathrm{Ir}_{0.3} \mathrm{O}_{3}$ might be considered as an intermediate state between the cubic perovskite-type structure $\mathrm{Sr}_{2} \mathrm{CoIrO}_{6}$ and the $\mathrm{Sr}_{3} \mathrm{CoIrO}_{6}$ structure (Figure $3 \mathrm{c}$ and $\mathrm{d})$; moving the $(\mathrm{Co}, \mathrm{Ir})_{2} \mathrm{O}_{9}$ units along the $[-110]$ direction in hexagonal $\mathrm{BaCo}_{0.7} \mathrm{Ir}_{0.3} \mathrm{O}_{3}$ would lead to chains similar to the ones in the $\mathrm{Sr}_{3} \mathrm{CoIrO}_{6}$ structure.

The iridium elimination from $\mathrm{Sr}_{2} \mathrm{CoIrO}_{6-\delta}$ during annealing in $\mathrm{Ar}$ atmosphere should cause a slight $\mathrm{Co}$

(14) Kepert, D. L. In Comprehensive Coordination Chemistry; Pergamon Press: Oxford, U.K., 1987; Vol. 1.

(15) Mikhailova, D.; Senyshyn, A.; Schwarz, B.; Ehrenberg, H., in prep.

(16) Vente, J. F.; Battle, P. D. J. Solid State Chem. 2000, 152, 361-373. 
Table 1. Structural Parameters for Two Compositions $\mathrm{Sr}_{2} \mathrm{CoIrO}_{6.00}$ and $\mathrm{Sr}_{2} \mathrm{CoIrO}_{5.80}$ at 300 and $3 \mathrm{~K}$ from Neutron Powder Diffraction Data ${ }^{a}$

\begin{tabular}{|c|c|c|c|c|c|}
\hline \multirow[b]{2}{*}{ temperature } & $\mathrm{Sr}_{2} \mathrm{CoIrO}_{6.00}$ & $\mathrm{Sr}_{2} \mathrm{CoIrO}_{5.80}$ & $\mathrm{Sr}_{2} \mathrm{CoIrO}_{6.00}$ & $\mathrm{Sr}_{2} \mathrm{CoIrO}_{6.00}$ & $\mathrm{Sr}_{2} \mathrm{CoIrO}_{5.80}$ \\
\hline & $300 \mathrm{~K}$ & $300 \mathrm{~K}$ & $3 \mathrm{~K}$ & $3 \mathrm{~K}$ & $3 \mathrm{~K}$ \\
\hline space group & $I 2 / m$ & $I 4 / m$ & $I 2 / m$ & $P 2_{1} / n$ & $I 4 / m$ \\
\hline$a(\AA)$ & $5.5134(2)$ & $5.5369(1)$ & $5.4904(4)$ & $5.5684(2)$ & $5.5235(1)$ \\
\hline$b(\AA)$ & $5.5302(2)$ & $5.5369(1)$ & $5.5072(4)$ & $5.5323(2)$ & $5.5235(1)$ \\
\hline$c(\AA)$ & $7.8241(2)$ & $7.8273(3)$ & $7.8415(7)$ & $7.6936(2)$ & $7.8096(4)$ \\
\hline$\beta\left({ }^{\circ}\right)$ & $90.353(2)$ & 90 & $90.374(6)$ & $90.108(5)$ & 90 \\
\hline$V\left(\AA^{3}\right)$ & $238.56(1)$ & $239.96(1)$ & $237.09(3)$ & 237.01(1) & $238.26(1)$ \\
\hline$Z$ & 2 & 2 & 2 & 2 & 2 \\
\hline $\mathrm{Sr}$ & $4 i$ & $4 d$ & $4 i$ & $4 e$ & $4 d$ \\
\hline$x$ & $0.494(1)$ & 0.5 & $0.523(1)$ & $0.4994(9)$ & 0.5 \\
\hline$y$ & 0 & 0 & 0 & $0.006(2)$ & 0 \\
\hline$z$ & $0.7504(8)$ & 0.25 & $0.241(1)$ & $0.253(1)$ & 0.25 \\
\hline$B\left(\AA^{2}\right)$ & $0.65(2)$ & $0.80(2)$ & $0.30(4)$ & $0.30(4)$ & $0.47(2)$ \\
\hline \multirow[t]{2}{*}{$\operatorname{Co}(1)$} & $2 a(0,0,0)$ & $2 a(0,0,0)$ & $2 a(0,0,0)$ & $2 a(0,0,0)$ & $2 a(0,0,0)$ \\
\hline & $1-n=0.868$ & $1-n=0.864$ & $1-n=0.868$ & $1-n=0.868$ & $1-n=0.864$ \\
\hline \multirow[t]{2}{*}{$\operatorname{Co}(2)$} & $2 d(0,0,0.5)$ & $2 b(0,0,0.5)$ & $2 d(0,0,0.5)$ & $2 b(0,0,0.5)$ & $2 b(0,0,0.5)$ \\
\hline & $n=0.132$ & $n=0.136$ & $n=0.132$ & $n=0.132$ & $n=0.136$ \\
\hline$B\left(\AA^{2}\right)$ & $0.11(1)$ & $0.12(2)$ & $0.09(1)$ & $0.09(1)$ & $0.08(2)$ \\
\hline \multirow[t]{2}{*}{$\operatorname{Ir}(1)$} & $2 a(0,0,0)$ & $2 a(0,0,0)$ & $2 a(0,0,0)$ & $2 a(0,0,0)$ & $2 a(0,0,0)$ \\
\hline & $n=0.132$ & $n=0.136$ & $n=0.132$ & $n=0.132$ & $n=0.136$ \\
\hline \multirow[t]{2}{*}{$\operatorname{Ir}(2)$} & $2 d(0,0,0.5)$ & $2 b(0,0,0.5)$ & $2 d(0,0,0.5)$ & $2 b(0,0,0.5)$ & $2 b(0,0,0.5)$ \\
\hline & $1-n=0.868$ & $1-n=0.864$ & $1-n=0.868$ & $1-n=0.868$ & $1-n=0.864$ \\
\hline$B\left(\AA^{2}\right)$ & $0.11(1)$ & $0.12(2)$ & $0.09(1)$ & $0.09(1)$ & $0.08(2)$ \\
\hline $\mathrm{O}(1)$ & $4 i$ & $4 e$ & $4 i$ & $4 e$ & $4 e$ \\
\hline$x$ & $-0.0199(7)$ & 0 & $0.004(2)$ & $0.0479(4)$ & 0 \\
\hline$y$ & 0 & 0 & 0 & $0.0074(12)$ & 0 \\
\hline$z$ & $0.2514(4)$ & $0.2538(9)$ & $0.250(1)$ & $0.2474(4)$ & $0.253(1)$ \\
\hline sof $\mathrm{O}(1)$ & 1.00 & $0.91(1)$ & 1.00 & 1.00 & $0.91(1)$ \\
\hline$B\left(\AA^{2}\right)$ & $0.92(2)$ & $1.63(2)$ & $1.61(8)$ & $0.36(4)$ & $1.46(2)$ \\
\hline $\mathrm{O}(2)$ & $8 j$ & $8 h$ & $8 j$ & $4 e$ & $8 h$ \\
\hline$x$ & $0.2417(3)$ & $0.2730(3)$ & $0.2387(9)$ & $0.2728(6)$ & $0.2770(3)$ \\
\hline$y$ & $0.2634(4)$ & $0.2320(3)$ & $0.2687(8)$ & $0.2366(9)$ & $0.2290(3)$ \\
\hline$z$ & $0.0273(2)$ & 0 & $0.0273(6)$ & $0.9706(4)$ & 0 \\
\hline sof $O(2)$ & 1.00 & 1.00 & 1.00 & 1.00 & 1.00 \\
\hline$B\left(\AA^{2}\right)$ & $0.92(2)$ & $1.63(2)$ & $1.61(8)$ & $0.36(4)$ & $1.46(2)$ \\
\hline \multicolumn{4}{|l|}{$\mathrm{O}(3)$} & $4 e$ & \\
\hline \multirow{2}{*}{\multicolumn{4}{|c|}{$\begin{array}{l}x \\
y\end{array}$}} & $0.2426(7)$ & \\
\hline & & & & $0.7354(8)$ & \\
\hline \multicolumn{4}{|l|}{$\begin{array}{l}z \\
B\left(\AA^{2}\right)\end{array}$} & $0.9861(4)$ & \\
\hline \multicolumn{4}{|l|}{$B\left(\AA^{2}\right)$} & $0.36(4)$ & \\
\hline \multirow[t]{2}{*}{$\mathrm{Co}(\mathrm{Ir})-\mathrm{O}$} & $1.985(2) \times 4$ & $1.984(2) \times 4$ & $1.987(4) \times 4$ & \multirow{3}{*}{$\begin{array}{l}1.920(3) \times 2 \\
1.995(4) \times 2 \\
2.017(4) \times 2 \\
1.977(4)\end{array}$} & $1.985(2) \times 4$ \\
\hline & $1.971(3) \times 2$ & $1.987(1) \times 2$ & $1.960(10) \times 2$ & & $1.976(8) \times 2$ \\
\hline$\overline{\operatorname{Co}}(\overline{I r})-\bar{O}$ & $1.980(2)$ & $1.985(4)$ & $1.978(6)$ & & $1.982(4)$ \\
\hline \multirow[t]{2}{*}{$\operatorname{Ir}(\mathrm{Co})-\mathrm{O}$} & $1.947(2) \times 4$ & $1.945(2) \times 4$ & $1.932(4) \times 4$ & \multirow{4}{*}{$\begin{array}{l}1.965(3) \times 2 \\
1.943(4) \times 2 \\
1.939(4) \times 2 \\
1.949(4)\end{array}$} & $1.939(2) \times 4$ \\
\hline & $1.948(3) \times 2$ & $1.927(7) \times 2$ & $1.964(10) \times 2$ & & $1.929(8) \times 2$ \\
\hline$\overline{\operatorname{Ir}}(\overline{C o})-\bar{O}$ & $1.947(2)$ & $1.939(4)$ & $1.942(6)$ & & $1.936(4)$ \\
\hline \multicolumn{5}{|l|}{ Bragg } & \\
\hline$R$ factor, $\%$ & 4.02 & 4.84 & 3.91 & 5.25 & 4.69 \\
\hline$R_{\mathrm{f}}$ factor, $\%$ & 2.86 & 3.51 & 2.22 & 3.81 & 3.39 \\
\hline
\end{tabular}

${ }^{a}$ The cation disorder $n$ was determined by XRD at room temperature for the monoclinic and tetragonal modifications and fixed in the structure refinements, based on neutron powder diffraction data, ans sof is the site occupation factor.

excess in the structure of the nondecomposed " $\mathrm{Sr}_{2} \mathrm{Co}_{1+x}$ " $\mathrm{Ir}_{1-x} \mathrm{O}_{6-\delta}$ ". The cell volume of " $\mathrm{Sr}_{2} \mathrm{CoIrO}_{6-\delta}$ " after heat treatment at $1573 \mathrm{~K}$ in $\operatorname{Ar}\left(F m-3 m, 484.63(2) \AA^{3}\right)$ is smaller than the volume of $\mathrm{Sr}_{2} \mathrm{CoIrO}_{6-\delta}$ annealed at $1273 \mathrm{~K}$ in $\operatorname{Ar}\left(F m-3 m, 485.99(1) \AA^{3}\right)$, in contrast to the common tendency that cell volumes in perowskites increase with decreasing oxygen contents. This indicates a slightly different cation stoichiometry of " $\mathrm{Sr}_{2} \mathrm{CoIrO}_{6-\delta}$ " before and after calcination in Ar at $1573 \mathrm{~K}$.

2. In situ Crystal Structure Investigations of $\mathrm{Sr}_{2}$ $\mathrm{CoIrO}_{6.00}$ and $\mathrm{Sr}_{2} \mathrm{CoIrO}_{5.80}$ at Elevated Temperatures in Air and Ar. The crystal symmetry of the solid solution $\mathrm{Sr}_{2} \mathrm{CoIrO}_{6-\delta}$ is strongly dependent on temperature and oxygen stoichiometry. Temperature-induced symmetry changes with preserved stoichiometry are caused by tiltings of $\mathrm{CoO}_{6}$ and $\mathrm{IrO}_{6}$ octahedra. ${ }^{12}$ The crystal structure of $\mathrm{Sr}_{2} \mathrm{CoIrO}_{6-\delta}$ without oxygen deficiency $(\delta=0)$ is monoclinic $(I 2 / \mathrm{m})$ at room temperature and was refined, based on neutron powder diffraction data (Table 1). The cation disorder " $n$ " is a measure for the mixed occupation of $\mathrm{Co}$ and $\mathrm{Ir}$ on one specific site. The value of $n$ corresponds to the relative amount of the minor element on these sites: $n=0$ refers to complete order and $n=0.5$ to $50 \%$ of Ir on the Co site and vice versa, i.e., a random distribution of $\mathrm{Co}$ and $\mathrm{Ir}$ on both sites. Synchrotron measurements in air showed a sequence of phase transitions at elevated temperatures, with increasing temperature it becomes tetragonal $(I 4 / m)$ and cubic 
(a)

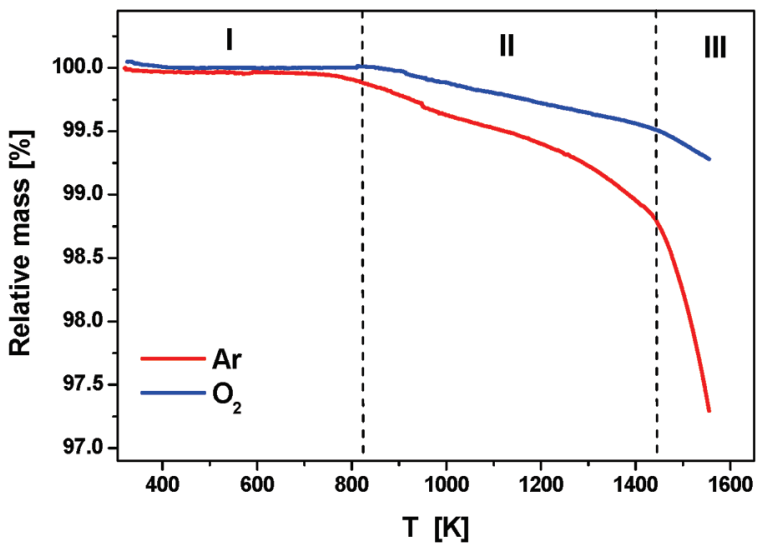

(c)

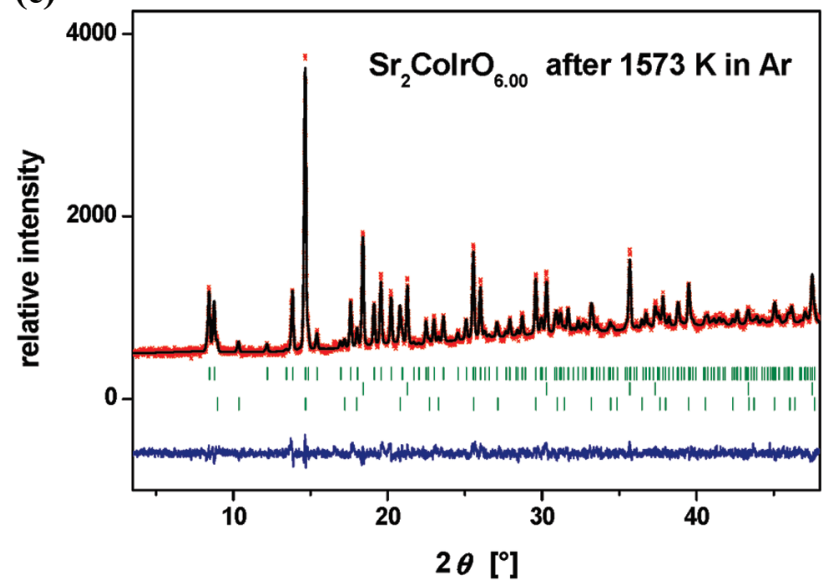

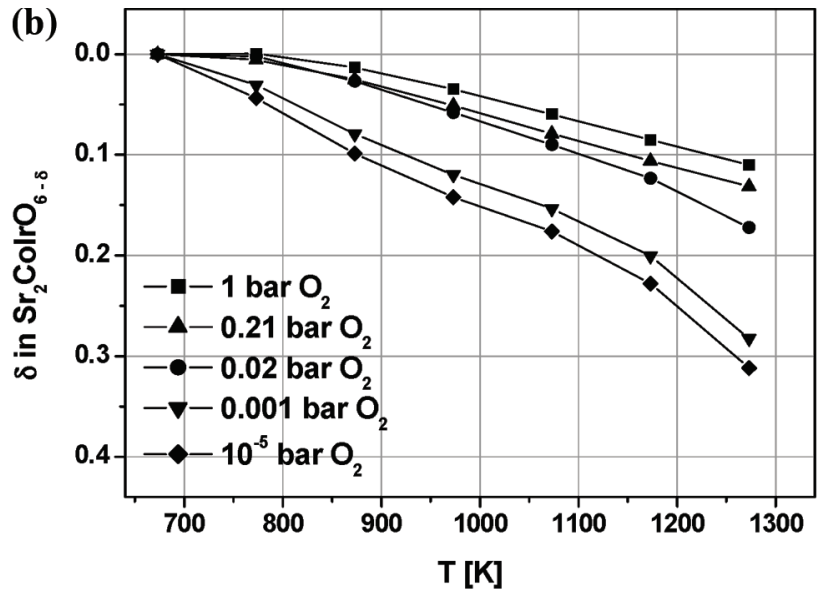

(d)

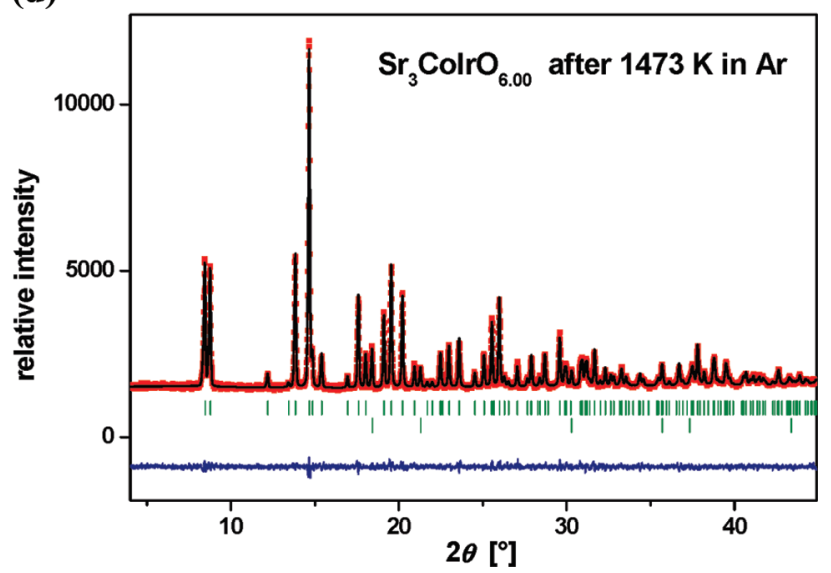

Figure 2. (a) TGA curves of $\mathrm{Sr}_{2} \mathrm{CoIrO}_{6.00}$ in $\mathrm{Ar}$ and $\mathrm{O}_{2}$ flow. From these data, three different regions of mass loss can be distinguished. (b) Temperature dependence of oxygen deficiency $\delta$ in $\mathrm{Sr}_{2} \mathrm{CoIrO}_{6-\delta}$ at different oxygen pressures. (c) X-ray diffraction pattern of "Sr${ }_{2} \mathrm{CoIrO}_{6.00}$ " after annealing in Ar at $1573 \mathrm{~K}$; observed and calculated profiles together with their difference curve. Tick marks represent from top to bottom the positions of reflections for a new phase $\mathrm{Sr}_{3} \mathrm{CoIrO}_{6}(R-3 c)$, metallic $\mathrm{Ir}(F m-3 m)$, and $\mathrm{Sr}_{2} \mathrm{Co}_{1+x} \mathrm{Ir}_{1-x} \mathrm{O}_{6-\delta}(F m-3 m)$. (d) X-ray diffraction pattern of $\mathrm{Sr}_{3} \mathrm{CoIrO}_{6.00}$, prepared at $1473 \mathrm{~K}$ in $\mathrm{Ar}$, observed and calculated profiles, based on the $\mathrm{K}_{4} \mathrm{CdCl}_{6}$ structural model, together with their difference curve. Tick marks represent from top to bottom the positions of reflections for $\mathrm{Sr}_{3} \mathrm{CoIrO}_{6}(R-3 c)$ and metallic $\operatorname{Ir}(F m-3 m, 2.5 \% \mathrm{w} / \mathrm{w})$.

$(F m-3 m): I 2 / m \stackrel{620 \mathrm{~K}}{\leftrightarrow} I 4 / m \stackrel{700 \mathrm{~K}}{\leftrightarrow} F m-3 m$. There is no significant change of oxygen content in air at these temperatures according to thermogravimetric measurements (Figure 2b). In contrast to $\mathrm{Sr}_{2} \mathrm{CoIrO}_{6.00}$, the crystal structure of the oxygen-deficient compound $\mathrm{Sr}_{2} \mathrm{CoIrO}_{5.80}$, obtained from the stoichiometric phase through annealing at $1123 \mathrm{~K}$ in $\mathrm{Ar}$ atmosphere, is tetragonal $(\mathrm{I} / \mathrm{m})$ at room temperature (Table 1). The oxygen vacancies are unambiguously on the $4 e$ site $(0,0, z)$, whereas the $8 h$ site $(x, y, 0)$ remains fully occupied by oxygen. The oxygen content determined from neutron diffraction (5.81(1)) is in agreement with thermogravimetric data $(5.80(2))$. The analysis of room temperature neutron diffraction data from two compounds with tetragonal symmetry and with different oxygen contents revealed that oxygens are removed from the sites which correspond to the shortest $\mathrm{Co}-\mathrm{O}$ and $\mathrm{Ir}-\mathrm{O}$ distances in both $\mathrm{CoO}_{6}$ and $\mathrm{IrO}_{6}$ octahedra, indicating a partial reduction of $\mathrm{Co}$ and Ir. The authors of ref 18 deduced a dependence of the average

(17) Howard, C. J.; Kennedy, B. J.; Woodward, P. M. Acta Crystallogr. 2003, B59, 463-471.

(18) Choy, J.-H.; Kim, D.-K.; Hwang, S.-H.; Demazeau, G.; Jung, D.-Y. J. Am. Chem. Soc. 1995, 117, 8557-8566.
$\mathrm{Ir}-\mathrm{O}$ bond distance on the oxidation state of $\mathrm{Ir}$ in double perovskites with only Ir as a transition-metal ion: it corresponds to 2.00, 1.96, and $1.925 \AA$ for $\mathrm{Ir}^{4+}, \mathrm{Ir}^{5+}$, and $\mathrm{Ir}^{6+}$, respectively. For stabilizing the high-oxidation states of $\mathrm{Ir}^{5+}$ and $\operatorname{Ir}^{6+}$, the phases have been treated under high-temperature and high-oxygen pressure conditions. The average $\mathrm{Ir}-\mathrm{O}$ bond lengths in $\mathrm{Sr}_{2} \mathrm{CoIrO}_{6-\delta}(1.93-1.94 \AA)$ are a strong evidence for mixed $\mathrm{Ir}^{5+} / \mathrm{Ir}^{6+}$ states.

High-temperature neutron diffraction studies up to $970 \mathrm{~K}$ were performed in Ar atmosphere on two samples $\mathrm{Sr}_{2} \mathrm{CoIrO}_{6-\delta}$ with $\delta=0$ and 0.2 . The crystal structures change from monoclinic via tetragonal to cubic $(I 2 / \mathrm{m} \rightarrow$ $I 4 / m \rightarrow F m-3 m)$ for $\mathrm{Sr}_{2} \mathrm{CoIrO}_{6.00}$ and from tetragonal to cubic $I 4 / m \rightarrow F m-3 m$ for $\mathrm{Sr}_{2} \mathrm{CoIrO}_{5.80}$. In the temperature region I (see Figure 2a) the atmosphere does not play a significant role, and symmetry changes are induced by temperature and not by oxygen vacancies. At the highest temperature of $970 \mathrm{~K}$ in temperature region II, oxygen release becomes relevant, and the sample with initial composition $\mathrm{Sr}_{2} \mathrm{CoIrO}_{6.00}$ showed a significant oxygen deficiency after cooling to room temperature in Ar atmosphere. Neutron powder diffraction revealed tetragonal symmetry and $\delta=0.17(4)$ in very good agreement with 


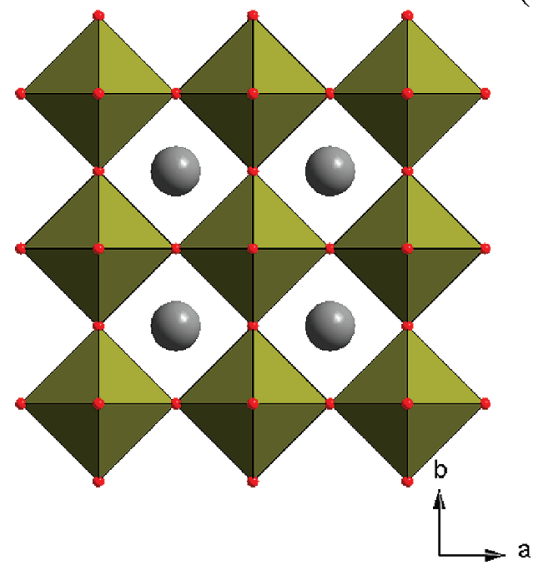

(a)

(b)
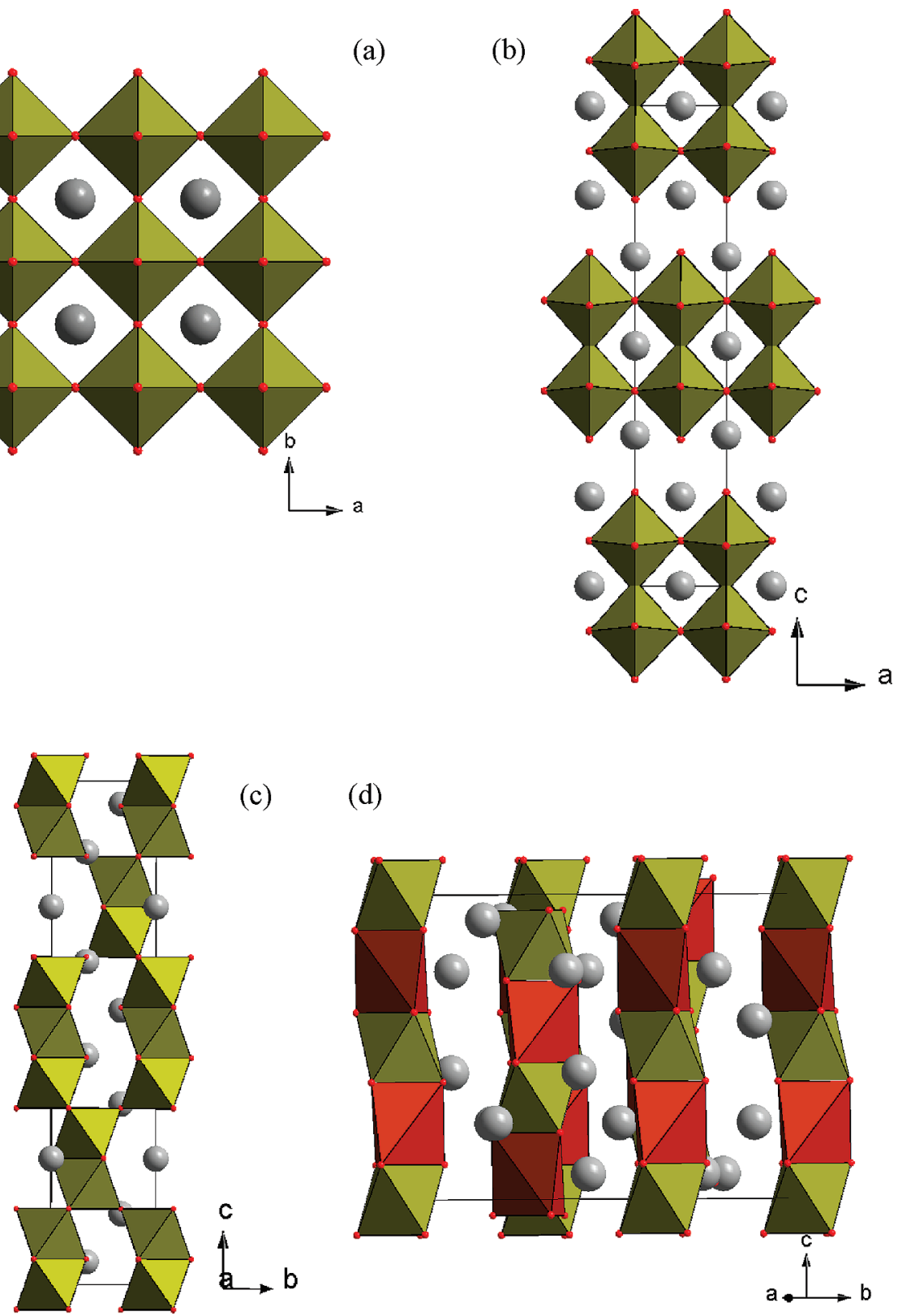

(d)

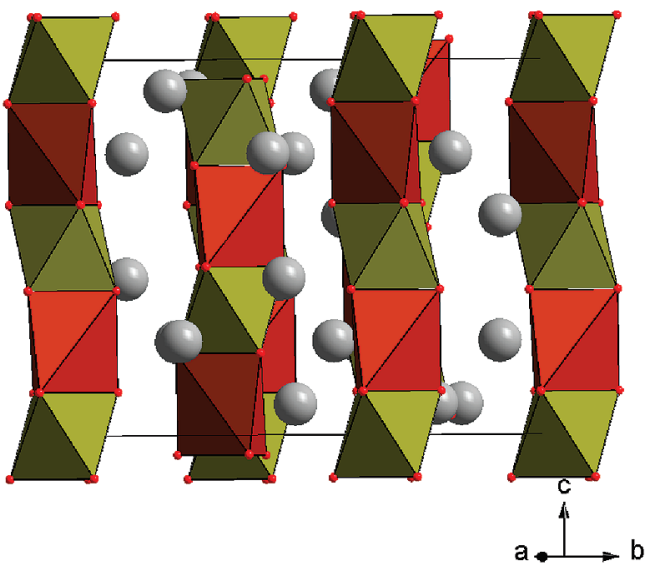

Figure 3. From left to right: (a) the structure of the cubic double perovskite phase $\mathrm{Sr}_{2} \mathrm{CoIrO}_{6}$, (b) the tetragonal Ruddlesden-Popper structure of $\mathrm{Sr}_{3}\left(\mathrm{Mo}_{1-x} \mathrm{Mg}_{x}\right)_{2} \mathrm{O}_{7-\delta}$, (c) the hexagonal perovskite $\mathrm{BaCo}_{0.7} \mathrm{Ir}_{0.3} \mathrm{O}_{3}$, (d) the $\mathrm{Sr}_{3} \mathrm{CoIrO}_{6}$ with $\mathrm{K}_{4} \mathrm{CdCl}_{6}$-type structure and a $\mathrm{Co} / \mathrm{Ir}$ order on distinct sites. Light-gray spheres represent $\mathrm{Sr}$ atoms.

the thermogravimetric data $\delta=0.15(2)$. Both parameters, temperature and oxygen deficiency, increase the crystal symmetry of $\mathrm{Sr}_{2} \mathrm{CoIrO}_{6-\delta}$ or, in other words, oxygen deficiency reduces the transition temperatures but is not a precondition for higher symmetries. A higher amount of vacancies will promote the dynamics of lattice processes and, hereby, contribute to an averaging of local deviations from higher symmetries, as caused, for example, by $\mathrm{Co}^{2+}$ in oxygen-deficient phases by the more pronounced geometrical mismatch between $\mathrm{Co}^{2+}-\mathrm{O}$ and $\mathrm{Ir}-\mathrm{O}$ bonds than for $\mathrm{Co}^{3+}$. Therefore, higher symmetric structures are supported by oxygen vacancies, as observed by diffraction. In addition, the empirical Goldschmidt tolerance factor $t=\frac{d(\mathrm{Sr}-\mathrm{O})}{\sqrt{2}\left(\frac{d(\mathrm{Co}-\mathrm{O})+d(\mathrm{Ir}-\mathrm{O})}{2}\right)}$, which is nearly 1 for a cubic perovskite structure and deviates more and more from 1 for lower symmetries, ${ }^{13}$ is 0.984 for the higher symmetric oxygen-defficient $\mathrm{Sr}_{2} \mathrm{CoIrO}_{5.80}$ phase and closer to 1 than $t=0.975$ for the lower symmetric phase $\mathrm{Sr}_{2} \mathrm{CoIrO}_{6.00}$ without oxygen vacancies.

3. Low-Temperature Structural Behavior of $\mathrm{Sr}_{2} \mathrm{Coiro}_{6.00}$ and $\mathrm{Sr}_{2} \mathrm{Coiro}_{5.80}$. The low-temperature structural behavior of $\mathrm{Sr}_{2} \mathrm{CoIrO}_{6.00}$ and $\mathrm{Sr}_{2} \mathrm{CoIrO}_{5.80}$ is different. Synchrotron and neutron experiments revealed a structural phase transition $I 2 / m \rightarrow P 2_{1} / n$ of stoichiometric $\mathrm{Sr}_{2} \mathrm{CoIrO}_{6.00}$ with a coexistence of both modifications below $220 \mathrm{~K}$ (Figures $4 \mathrm{a}$ and $\mathrm{b}$ and 5), whereas oxygen deficient $\mathrm{Sr}_{2} \mathrm{CoIrO}_{5.80}$ does not demonstrate any change in lattice symmetry but only a decrease of the average interatomic $\mathrm{Co}-\mathrm{O}$ and $\mathrm{Ir}-\mathrm{O}$ distances at lower temperature (Table 1). Attempts to explain the low-temperature diffraction data 

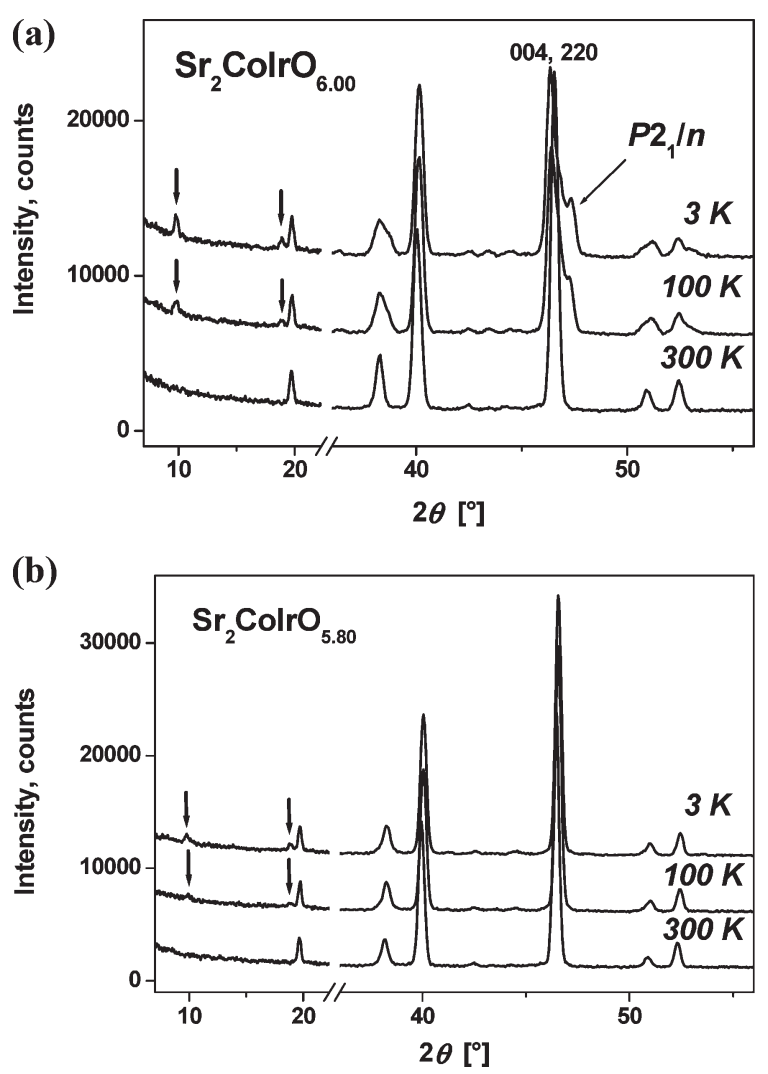

Figure 4. Evolution of neutron powder diffraction patterns of (a) $\mathrm{Sr}_{2} \mathrm{CoIrO}_{6.00}$ and (b) $\mathrm{Sr}_{2} \mathrm{CoIrO}_{5.80}$ with decreasing temperature $(\lambda=$ $1.5424 \mathrm{~A}$ ). Below $100 \mathrm{~K}$ magnetic reflections appear in both diffraction patterns (marked by arrows). For $\mathrm{Sr}_{2} \mathrm{CoIrO}_{6.00}$ a structural phase transition $I 2 / m \rightarrow P 2_{1} / n+I 2 / m$ is observed below $220 \mathrm{~K}$.

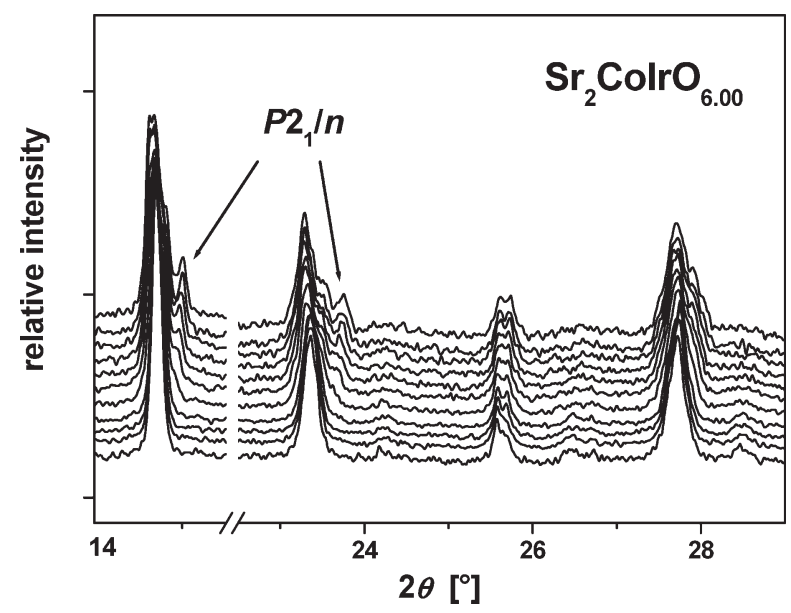

Figure 5. A section of synchrotron powder diffraction patterns $(\lambda=$ $0.50206 \AA$ ) of $\mathrm{Sr}_{2} \mathrm{CoIrO}_{6.00}$, recorded for increasing temperatures between 100 and $300 \mathrm{~K}$ in steps of $20 \mathrm{~K}$ (from top to bottom), revealing the existence of a two-phase region with $I 2 / m$ and $P 2_{1} / n$ structures below $220 \mathrm{~K}$.

based on the $I-1$ structural model analogous to $\mathrm{Ba}_{2} \mathrm{LaIrO}_{6}{ }^{19}$ led to much worse R-values and an unsatisfactory description of diffraction patterns. The relative amount of the $I 2 / \mathrm{m}$ modification in $\mathrm{Sr}_{2} \mathrm{CoIrO}_{6.00}$ decreases with decreasing temperature as expected for a metastable phase, which is still coexisting after a first-order phase transition.

(19) Zhou, Q.; Kennedy, B. J.; Avdeev, M.; Giachini, L.; Kimpton, J. A. J. Solid State Chem. 2009, 182, 3195-3200.

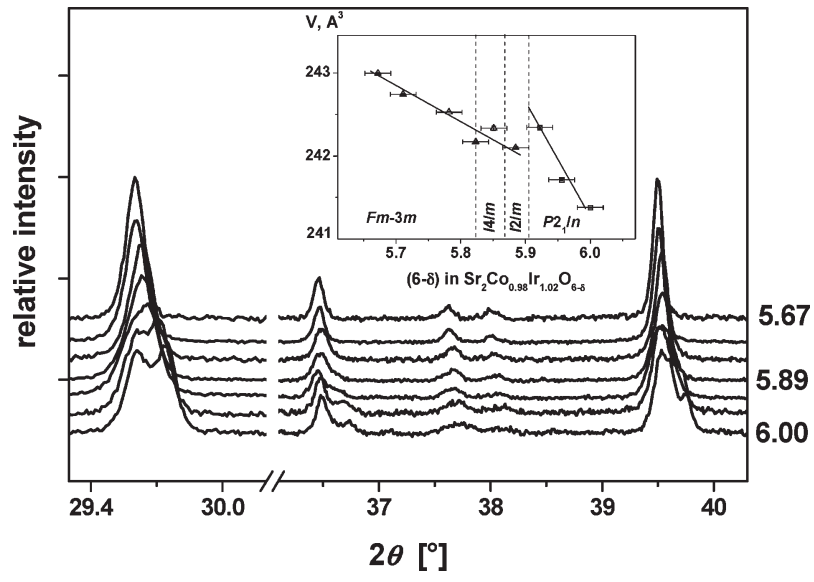

Figure 6. X-ray diffraction patterns of $\mathrm{Sr}_{2} \mathrm{Co}_{0.98(2)} \mathrm{Ir}_{1.02(2)} \mathrm{O}_{6-\delta}$ (from top to bottom: $6-\delta=5.67,5.78,5.85,5.89,5.92,5.96$, and 6.00 ), measured at room temperature. The evolution of the unit cell volume in dependence on the oxygen content is shown in the inset. At $6-\delta \leq$ 5.90, a first-order structural phase transition from $P 2_{1} / n$ to $I 2 / m$ was observed, whereas a sequence of second-order phase transitions $I 2 / m^{6-\delta \approx 5.86} I 4 / m \stackrel{6-\delta \approx 5.82}{\leftrightarrow} \mathrm{Fm}-3 \mathrm{~m}$ takes place during further reduction.

An analysis of the average metal-oxygen distances in $I 2 / m$ at room temperature and $3 \mathrm{~K}$ and in $P 2_{1} / n$ at $3 \mathrm{~K}$ does not indicate any partial charge transfer from Co to Ir.

4. Crystal Structure Investigations of $\mathrm{Sr}_{2} \mathrm{Co}_{0.98} \mathrm{Ir}_{1.02}$ $\mathrm{O}_{6-\delta}$ in Dependence on Oxygen Content. The low-temperature modification $P 2_{1} / n$ of $\mathrm{Sr}_{2} \mathrm{Co}_{1-x} \mathrm{Ir}_{1+x} \mathrm{O}_{6.00}$ seems to be stabilized at room temperature by a small excess of $\operatorname{Ir}(x=0.02)$ as observed for a sample, obtained by slow cooling in air after synthesis. Samples with different oxygen contents were prepared based on the $\delta-\mathrm{T}$ phase diagram (Figure $2 b$ ). Systematic investigations of the influence of the oxygen content $\delta$ on structural features of $\mathrm{Sr}_{2} \mathrm{Co}_{0.98} \mathrm{Ir}_{1.02} \mathrm{O}_{6-\delta}$ at room temperature have shown the change of symmetry from $P 2_{1} / n$ to $I 2 / m$ at $\delta \approx 5.90$, from $I 2 / m$ to $I 4 / m$ at $\delta \approx 5.86$, and from $I 4 / m$ to $F m-3 m$ at $\delta \approx 5.82$ (Figure 6). In order to distinguish $P 2_{1} / n$ from $I 2 / \mathrm{m}$ on one hand and $I 2 / \mathrm{m}$ from $I 4 / \mathrm{m}$ on the other, the instrumental resolution function was determined for a $\mathrm{Si}$ X-ray powder reference material (NBS 640b) and explicitly used for structure analysis using the Fullprof program within the WINPLOTR package. ${ }^{11}$ This improves the sensitivity against a broadening of selected reflections caused by an unresolved splitting of reflections in the case of lower symmetry. A decrease of the oxygen content in $\mathrm{Sr}_{2} \mathrm{Co}_{0.98} \mathrm{Ir}_{1.02} \mathrm{O}_{6-\delta}$ is accompanied by an increase of the unit cell volume (see insert in Figure 6). The symmetry changes from $P 2_{1} / n$ to $I 2 / m$ and shows a discontinuity in the cell volume, which is characteristic for a first-order phase transition as expected, because the space groups of the two phases do not obey a group-subgroup relationship. ${ }^{17}$

5. Magnetic Properties of $\mathrm{Sr}_{2} \mathrm{CoIrO}_{6-\delta}$ in Dependence on Oxygen Stoichiometry. The temperature dependences of magnetization depend strongly on oxygen deficiency, as shown in Figure 7. Curie-Weiss temperature $\theta$ and paramagnetic moment $\mu$, deduced from Curie-Weiss fits to the temperature dependences of magnetization in the paramagnetic regions, show pronounced extrema at $6-$ $\delta \approx 5.90$, which corresponds to the phase boundary between the $P 2_{1} / n$ and $I 2 / m$ modifications (Figure 8 ). On the 

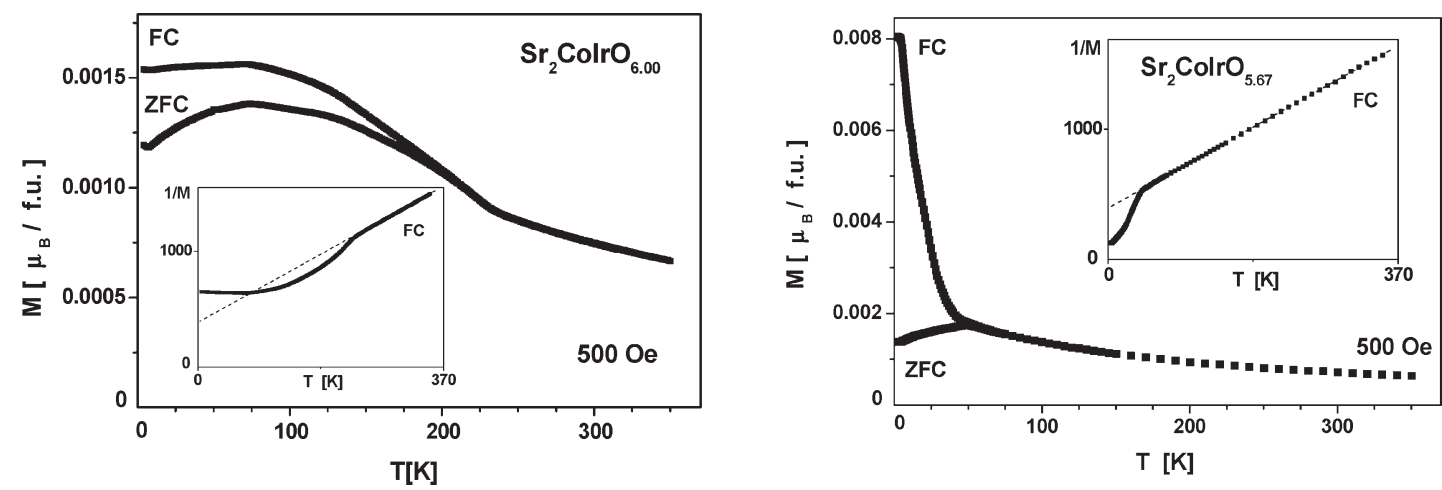

Figure 7. Temperature dependences of magnetization and inverse magnetization for $\mathrm{Sr}_{2} \mathrm{Co}_{0.98(2)} \mathrm{Ir}_{1.02(2)} \mathrm{O}_{6-\delta}$ with $\delta=0.00$ (left) and 0.33 (right).
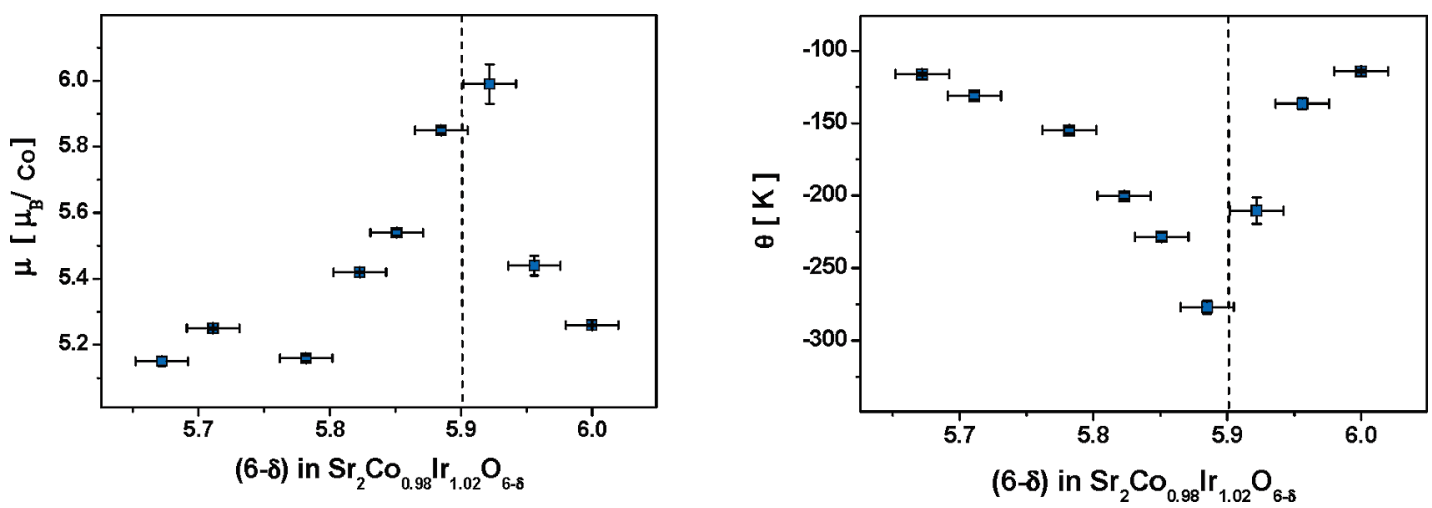

Figure 8. Effective paramagnetic moment $\mu$ (left), calculated per Co atom in the structure, and paramagnetic Curie-temperature $\theta$ (right) as functions of oxygen content in $\mathrm{Sr}_{2} \mathrm{Co}_{0.98(2)} \mathrm{Ir}_{1.02(2)} \mathrm{O}_{6-\delta}$. The dashed line corresponds to the first-order phase transition $P 2_{1} / n \leftrightarrow I 2 / m$.

other hand, the magnetic ordering temperature $T_{\mathrm{C}}$, defined as the onset temperature for significant deviations between measured magnetizations and extrapolated Curie-Weiss fits, decreases monotonously with oxygen deficiency, see Figure 9. The interpretation of the effect of oxygen deficiency on magnetic properties is very complex and reflects changes in the electronic structures of both transition metals Co and Ir in the region of the structural phase transition.

Neutron diffraction data show some additional reflections below $100 \mathrm{~K}$ at low diffraction angles, similar for both phases $\mathrm{Sr}_{2} \mathrm{CoIrO}_{6.00}$ and $\mathrm{Sr}_{2} \mathrm{CoIrO}_{5.80}$ and explained by magnetic ordering with the propagation vector $\vec{k}=(0$, $1 / 2,1 / 2$ ) (Figure 8). Ordered magnetic moments along the $c$-axes of 2.2(1) $\mu_{\mathrm{B}}$ for tetragonal $\mathrm{Sr}_{2} \mathrm{CoIrO}_{5.80}$ and 2.1(1) $\mu_{\mathrm{B}}$ for monoclinic $\mathrm{Sr}_{2} \mathrm{CoIrO}_{6.00}$ at $3 \mathrm{~K}$ were refined on the Co sites. It is not possible to distinguish from neutron powder diffraction data alone which structural modification, $I 2 / m$ or $P 2_{1} / n$, is responsible for the magnetic ordering in $\mathrm{Sr}_{2} \mathrm{CoIrO}_{6.00}$, because the magnetic Co- and Ir-cation sublattices are nearly the same for both phases (Table 1). The refined magnetic moment of 2.1(1) $\mu_{\mathrm{B}}$ is based on the assumption that both phases contribute to the magnetic Bragg reflections with the same magnetic moments (Figure 10)). Otherwise, magnetic moments of $3.4 \mu_{\mathrm{B}}$ would result if only the $I 2 / \mathrm{m}$ modification $(\sim 38 \% \mathrm{w} / \mathrm{w})$ would order magnetically and $2.7 \mu_{\mathrm{B}}$ for the $P 2_{1} / n$ modification only.

A noncollinear magnetism (NCM) can be concluded for all investigated $\mathrm{Sr}_{2} \mathrm{CoIrO}_{6-\delta}$ compounds, as already reported and discussed in detail for the end member

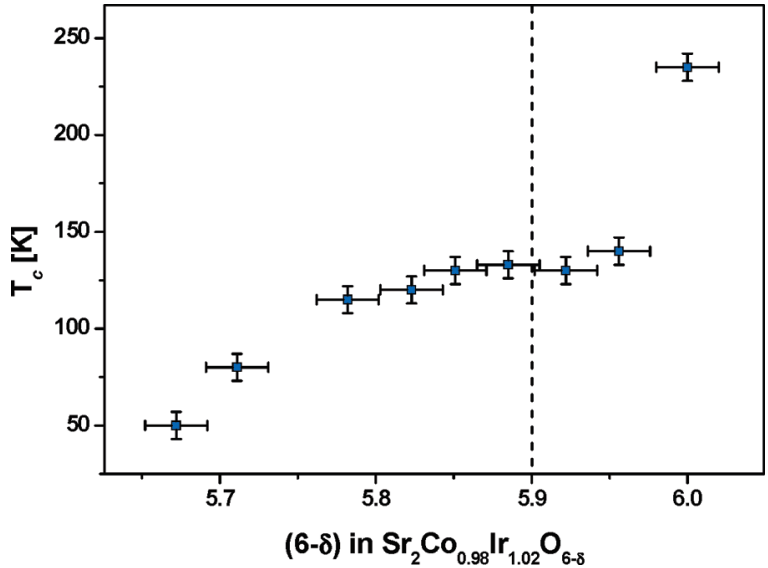

Figure 9. Dependence of the critical temperature $\left(T_{\mathrm{C}}\right)$, at which a significant deviation from the Curie-Weiss fit is observed, on oxygen content $6-\delta$. The dashed line corresponds to the first-order phase transition $P 2_{1} / n \leftrightarrow I 2 / m$.

$\mathrm{Sr}_{2} \mathrm{CoIrO}_{6.00}{ }^{7}$ On one hand, the propagation vector $\vec{k}=(0,1 / 2,1 / 2)$ indicates a dominant antiferromagnetic component. On the other hand, for all investigated compositions pronounced differences between ZFC and FC mode data were observed, reflecting a weak ferromagnetic component.

\section{Conclusion}

$\mathrm{Sr}_{2} \mathrm{CoIrO}_{6-\delta}$ phases with an average oxidation state of Ir between +5 and +6 can be synthesized in air without applying elevated oxygen pressure for stabilizing the 


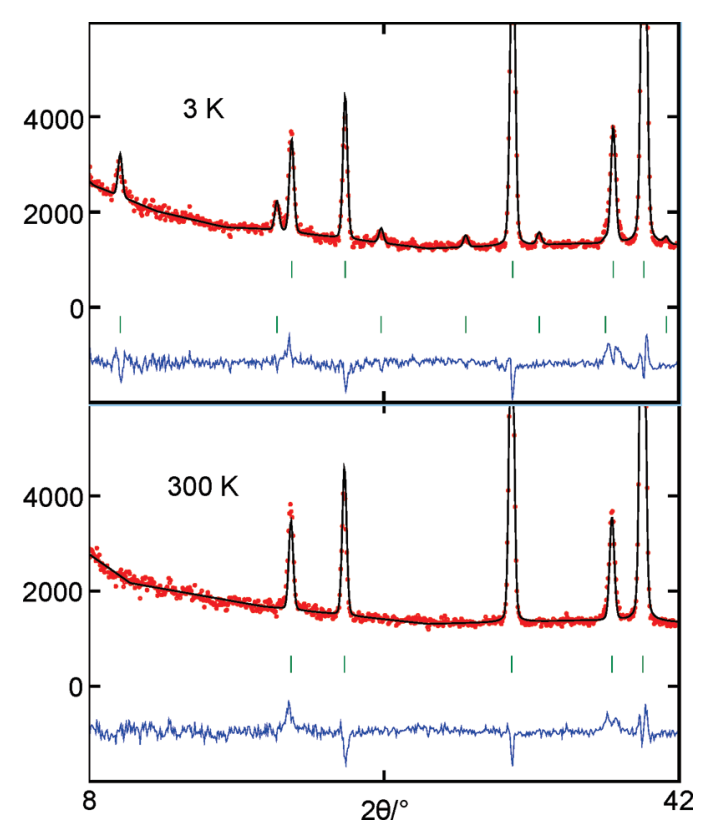

Figure 10. Low-angle section of the neutron diffraction patterns from $\mathrm{Sr}_{2} \mathrm{CoIrO}_{5.80}$. The positions of the magnetic Bragg reflections at $3 \mathrm{~K}$ are shown by the lower line of marks in the top figure; the other marks indicate the Bragg reflections from the crystal structure. Only the antiferromagnetic component along the $c$-axis was considered for the calculation of magnetic Bragg intensities, because the contributions from the ferromagnetic component were too weak to be detected by unpolarized neutron powder diffraction.

high-valence state of Ir. The oxygen content can be reversibly changed in the range of $0 \leq \delta \leq 0.33$, followed by a reversible decomposition into $\mathrm{Sr}_{3} \mathrm{CoIrO}_{6}, \mathrm{Sr}_{2} \mathrm{Co}_{1.5} \mathrm{Ir}_{0.5} \mathrm{O}_{6-\gamma}, \mathrm{Ir}$, and $\mathrm{O}_{2}$, dependent on temperature and oxygen pressure. For $\mathrm{Sr}_{2}-$ $\mathrm{CoIrO}_{6.00}$ without oxygen deficiency the sequence of phase transitions $I 2 / m+P 2_{1} / n \stackrel{220 \mathrm{~K}}{\leftrightarrow} I 2 / m^{620 \mathrm{~K}} \stackrel{\mathrm{C}}{\leftrightarrow} I 4 / m \stackrel{700 \mathrm{~K}}{\leftrightarrow} \mathrm{Fm}-3 m$ was observed in air. The formation of oxygen vacancies in $\mathrm{Sr}_{2} \mathrm{CoIrO}_{6-\delta}$ influences the structural features in a similar way as increasing temperature does; at the same temperature the oxygen-deficient phases crystallize with higher symmetry than the fully oxidized one, and a phase transition $I 4 / m \leftrightarrow$ $F m-3 m$ was observed for $\mathrm{Sr}_{2} \mathrm{CoIrO}_{5.80}$ at elevated temperature in $\mathrm{Ar}$ atmosphere. Neutron diffraction experiments reveal unambiguously that oxygen is released from the $4 e$ site, which corresponds to the shortest $\mathrm{Ir}-\mathrm{O}$ distance.
A small Ir excess, $\mathrm{Sr}_{2} \mathrm{Co}_{0.98} \mathrm{Ir}_{1.02} \mathrm{O}_{6.00}$, influences the crystal structure similar to decreasing temperature and reduces the symmetry to $P 2_{1} / n$ at room temperature in comparison to $I 2 / m$ for $\mathrm{Sr}_{2} \mathrm{Co}_{1.00} \mathrm{Ir}_{1.00} \mathrm{O}_{6.00}$. For the series $\mathrm{La}_{2-x} \mathrm{Sr}_{x} \mathrm{CoIrO}_{6.0}$ a decrease of the band gap is observed with increasing $\mathrm{Sr}$ content. An insulator to metal transition is not reached but approached from $\Delta E=0.26 \mathrm{eV}$ for $x=0$ to $0.05 \mathrm{eV}$ for $x=$ 1.5. Instead of the expected metallic behavior for $x=2$, a variable range hopping (VRH) was observed but was probably related to the high degree of cation disorder (15\%) in the $\mathrm{Co}$ and $\mathrm{Ir}$ distribution on the $\mathrm{M}$ and $\mathrm{M}^{\prime}$ sites. Furthermore, a transition from a mixture of intermediate- and high-spin IS/ $\mathrm{HS} \mathrm{Co}{ }^{2+}$ with low-spin $\mathrm{LS} \mathrm{Ir}^{4+}$ into $\mathrm{HS} \mathrm{Co}^{3+} / \mathrm{LS} \mathrm{Ir}^{5+}$ is postulated, based on the crystal structure investigations and theoretical density functional theory (DFT) calculations. ${ }^{7}$ The measured paramagnetic moments depend severely on the specific oxidation and spin states of the transition metals and, in combination, do not significantly change with strontium content. ${ }^{7}$ Both oxygen deficiency and a decrease of the $\mathrm{Sr}$ content result in a reduction of the transition metals on the $\mathrm{M}$ and $\mathrm{M}^{\prime}$ sites and, therefore, could affect the resulting physical properties in a similar way. However, anomalies in the dependence of paramagnetic moments and paramagnetic Curie-Weiss temperatures on oxygen content are observed and are clearly related to the first-order structural phase transition $P 2_{1} / n \stackrel{\delta \approx 0.10}{\longrightarrow} I 2 / m$, which does not take place with $\mathrm{Sr}$ substition in the fully oxidized phases. The structural changes due to the difference in ionic radii of $\mathrm{La}^{3+}$ and $\mathrm{Sr}^{2+}$ have a different effect on the magnetic properties of $\mathrm{La}_{2-x^{-}}$ $\mathrm{Sr}_{x} \mathrm{CoIrO}_{6.0}$ with $\mathrm{Sr}$ substition in comparison to those changes, which are induced by oxygen deficiency in $\mathrm{Sr}_{2}$ $\mathrm{CoIrO}_{6-\delta}$. Therefore, the physical properties are not entirely determined by the number of electrons on the Co and Ir sites but mainly by the underlying geometry for the slightly different specific crystal structures. A detailed explanation requires more information about the underlying electronic structures and the individual contributions from spin and orbital magnetic moments of Co and Ir. Such information might be accessible by an analysis of X-ray magnetic circular dichroism (XMCD).

Acknowledgment. This work has benefitted from financial support from the Bundesministerium für Bildung und Forschung and Deutsche Forschungsgemeinschaft (DFG). 